\title{
THE SPATIAL DISTRIBUTION PATTERNS OF THE CATERING TRADE IN NANCHANG BASED ON INTERNET PUBLIC REVIEWS
}

\author{
Xiong He ${ }^{1}$, Zijiang Yang ${ }^{1 *}$, Kun Zhang ${ }^{1}$, Ping Yang ${ }^{1}$, Shuai Zhang ${ }^{1}$ \\ ${ }^{1}$ School of Architecture and Urban Planning, Yunnan University, Kunming 650504, China
}

(Received: July 2018 / Revised: August 2018 / Accepted: December 2018)

\begin{abstract}
The spatial distribution characteristics and patterns of the catering industry in Nanchang were studied to determine the spatial laws of the local urban catering organizations. To establish a word-of-mouth evaluation system, the evaluation data of selected catering merchants were used to calculate comprehensive word-of-mouth scores and rankings for each merchant using principal component analysis. A nuclear density analysis of the spatial distribution of the catering industry was also carried out. The study results showed that Nanchang catering merchants can be divided into three groups of which high-consumption (the total amount of money spent by each customer at a single sitting) merchants accounted for $2.8 \%$, middleconsumption merchants accounted for $37 \%$, and low-consumption merchants accounted for $60.2 \%$. The catering industry's overall development level was further found to be low. Moreover, the high-consumption merchants were predominantly clustered in Honggutan, while the low-to-medium consumption merchants were mainly located in Zhongshan City. There was also a correlation between merchant distribution and merchant word-of-mouth: The distribution of catering chambers determined the level of word-of-mouth, and the degree of word-of-mouth determined the direction of catering development. Additionally, it was established that the internal business form and activity patterns of a city could affect the spatial distribution trends of catering merchants. Importantly, the study of network data combined with urban physical spaces could play a significant role in urban planning.
\end{abstract}

Keywords: Catering merchants; Nanchang; Public reviews; Spatial pattern

\section{INTRODUCTION}

People's daily lives and the internal organization of city spaces have changed enormously alongside the rapid development of information technology. To adapt to this trend, the theory of urban planning, the main aim of which is to study urban spatial organization and its changes, should seek to innovate its paradigms and methods. Such innovation is predominantly evident in the wide application of information technology in urban and regional research, the connections between network spaces and urban physical spaces, and discussions on the future of urban development (Zhen et al., 2007). Remote sensing, geographic information systems (GIS), and thermodynamic charts can be used to study urban spaces on a macro level (Wu \& Ye, 2016; Du et al., 2018). The data found in messages, blogs, locations, and people's daily lives can also be applied to study the behavioral characteristics of urban residents in microcosmic terms (Xiao et al., 2013; Ding et al., 2015; Li et al., 2016). Overall, paradigms and methods utilizing both network spaces and urban physical spaces are gradually increasing. The

\footnotetext{
* Corresponding author's email: ZJYang@ynu.edu.cn, Tel. +86-13708704422, Fax.+86-0871-65931900 Permalink/DOI: https://doi.org/10.14716/ijtech.v9i7.2485
} 
application of the big data of cities and their residents to urban network spaces is also becoming mainstream. However, the study of spatial organization and the structure of urban physical spaces is relatively lacking.

Scholars are paying increasing attention to the spatial distribution patterns of urban service industries, with their research scope covering commercial (Wu et al., 2003; Zhou \& Ji, 2009) and production services (Zhen et al., 2008; Xue et al., 2011). The catering trade is not only an important branch of commercial services, but also a necessary link in urban spatial organization. Diet, the environment, and culture merge to form a culture with a history. The catering trade is undoubtedly an extremely important feature of city life. Furthermore, the spatial distribution of the catering trade and its driving factors are greatly significant in guiding future urban construction. However, the study of the spatial distribution of the catering trade, which is proportional to the speed of a city's growth, is obviously not sufficient (Lu, 2007).

Foreign scholars have previously analyzed the spatial distribution of the catering trade from the perspective of tourism and transportation (Wall et al., 1985). They found that the catering trade is most concentrated in a city's central business district or in well-developed transportation areas. It was also established that there is a close connection between the urban catering trade and transportation, and a catering development model has therefore been proposed with roads and traffic as guides.

Domestic research started comparatively late and has focused primarily on the analysis of starrated hotels and hotel management (Hu \& Zhang, 2002; Wen, 2004). The volume of research concentrating on the spatial distribution of the catering trade is however low, and tended to be based on a single-subject design ( $\mathrm{Lu}, 2007)$.

Based on previous works, Nanchang was chosen as the sample study area in this paper and was evaluated using Statistical Product and Service Solutions (SPSS) with data from the review website Dianping. GIS was initially used to explore the spatial distribution of the catering trade in Nanchang.

\section{METHODS}

\subsection{Data Collection and Preprocessing}

The Dianping public comment network comprised the earliest third-party review platform in China. The model of the Dianping website was based on the Zagat Survey in the United States. Members of the website can publish their own comments and consumption opinions on restaurants through the website. After a certain level of information aggregation and organization, the website provides objective and accurate evaluation information to potential customers. As of December 2017, the number of active merchants on the Dianping website has reached nearly 250 million, and the number of reviews has exceeded 1.05 billion. It includes more than 20 million merchants, covering more than 2,500 cities in China, and nearly 1,000 cities in more than 200 countries and regions around the world. The website has in excess of 20 billion monthly page views and more than 400 million mobile client independent users. Among them, China Mobile's client traffic exceeds $85 \%$ of the website's monthly traffic. The website mainly focuses on food, entertainment, shopping, and other life service information. The most popular section, Food \& Beverages, has developed into a considerable library of word-of-mouth reviews that can influence customers' catering consumption decisions. With this in mind, this study explored the spatial distribution characteristics and patterns of the catering industry in Nanchang using the review data of registered merchants.

Nanchang's catering business data was obtained from Dianping's online public commentary, which comprised a total of 18,972 reviews. The information of 15,486 merchants was excluded 
because they did not have per capita consumption and had not received a star rating. (The absence of per capita consumption or a star rating indicates that customers pay little attention to such restaurants, which in turn translates into poor word-of-mouth reviews and low levels of patronage.) In the end, there was valid business information for 3,486 merchants. Google Maps was used to spatially locate and reconcile these merchants' spatial coordinates into geographic coordinates, and these were imported into ArcGIS.

The "level evaluation" of the website considers the evaluation level of the members but does not truly reflect the service quality of the restaurant merchants. It was therefore necessary to synthesize various sources of information to establish a reasonable evaluation index system and effectively measure the reputation of the catering merchants. According to the data provided by the Dianping website, the data was screened and an evaluation index system was established. The index evaluation system assessed six aspects: scale, grade evaluation, comment popularity, environmental quality, service quality, and overall effect (Table 1).

Table 1 The evaluation index system of the catering trade in nanchang

\begin{tabular}{cl}
\hline Evaluation index & Numerical score \\
\hline Scale & Per capita consumption \\
Level & Star level \\
Popularity & Number of comments \\
Environment & Environmental score \\
Service & Service score \\
\hline
\end{tabular}

\subsection{Data Analysis}

Based on the evaluation data of the 3,486 merchants and the results of the evaluation index system, a comprehensive analysis of the catering merchants was conducted based on a principal component analysis. First, the data were subjected to the Kaiser-Meyer-Olkin (KMO) test and the spherical Bartlett test. The results showed that the KMO value was 0.857, and the Bartlett test $\mathrm{P}$ value was 0.000 . This means that the correlation coefficient matrix and the identity matrix were significantly different. According to the KMO standard, the evaluation data could be subjected to a principal component analysis. At the same time, to better explain the degree of interpretation of each principal component, the variance of the initial factor load matrix was maximized and orthogonally rotated to obtain the eigenvalues of the three principal components. The cumulative variance contribution rate reached $78.31 \%$. According to the principle that the cumulative contribution rate should be greater than $75 \%$, the three factors after rotation could be used to explain the word-of-mouth level of the catering industry in Nanchang.

A comprehensive score calculation showed that the reputation scores of the catering merchants in Nanchang varied greatly, with the highest score reaching 2,775 and the lowest score being only 7 points (Figure 1). Most of the food and beverage merchants with high word-of-mouth scores had high ratings on the overall customer rating on the Dianping website, but the ratings of the food and beverage merchants with low word-of-mouth scores did not necessarily have low customer ratings. This is because these merchants had low membership levels and a small number of reviews, which affected their rating. Therefore, it was not possible to judge the reputation level of a restaurant merchant using only the rating evaluation. 


\section{RESULTS AND DISCUSSION}

\subsection{General Distribution of the Catering Merchants}

The spatial coordinates were converted into geographic coordinates by spatial location using Google Maps, and the geographic coordinates were subsequently imported into ArcGIS. The spatial distribution of the 3,486 identified merchants in Nanchang is shown in Figure 2.

Figure 2 shows that the geographic spread of the catering merchants was extensive. The kernel density of distribution of the catering merchants in Nanchang was obtained by a kernel density analysis in ArcGIS (Figure 3 Catering Merchants). The kernel density can represent the probability of the same event happening in different subregions of the same main area. It can also simply be called the aggregation density of events (Wang et al., 2010).

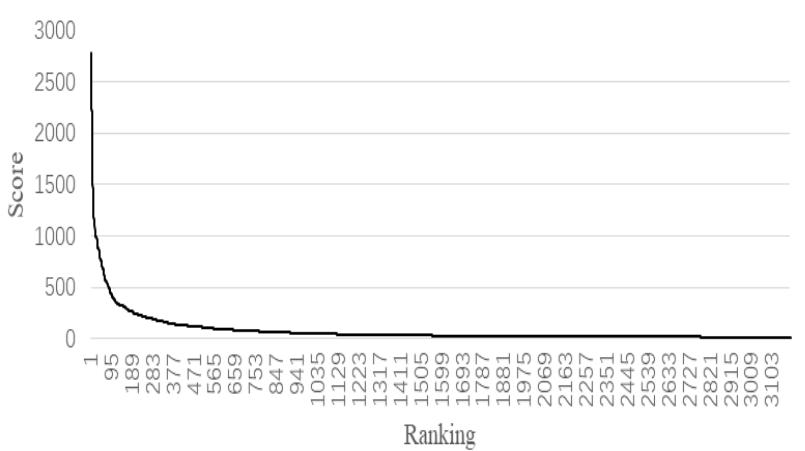

Figure 1 Curve of comprehensive scores

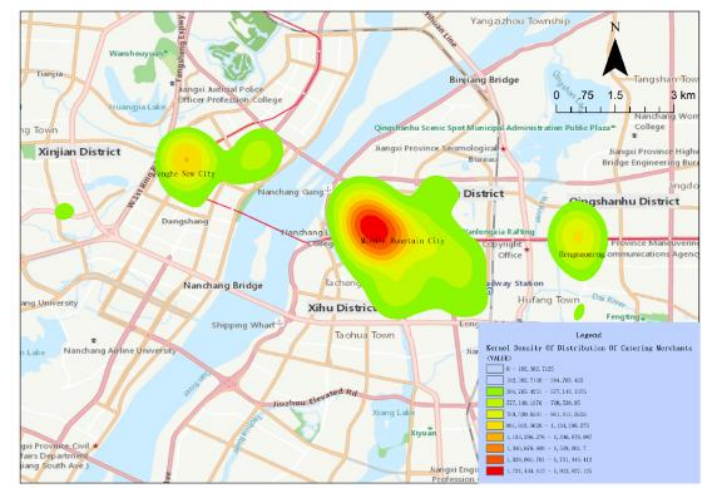

(a) Catering Merchants

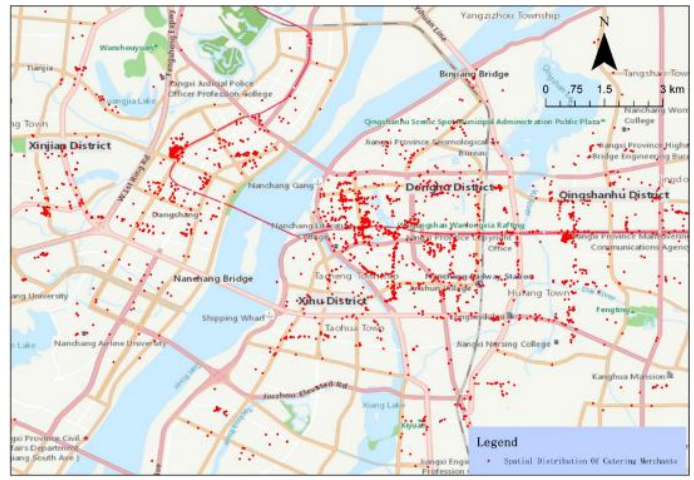

Figure 2 Spatial distribution of catering merchants

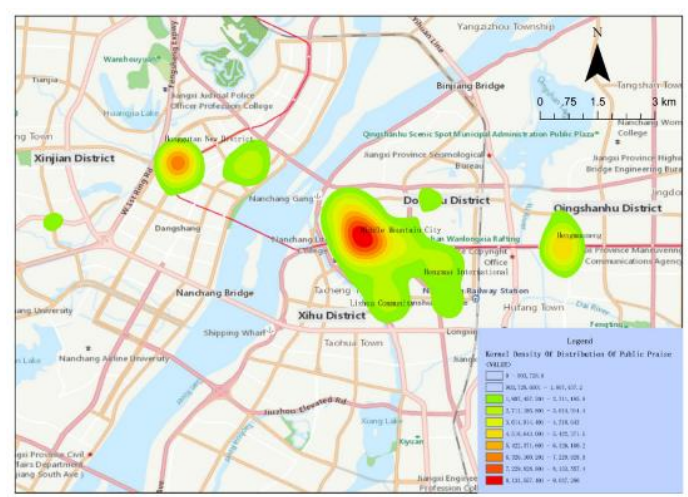

(b) Public Reviews

Figure 3 Kernel density of distribution

Figure 3 (Public reviews) indicates that Middle Mountain City had the highest distribution density. Its range aggregation was also much larger than that of other places and diffused to Baihua Continent and Yangzi Street. The distribution density and range of the Honggutan New District was smaller than those of Middle Mountain City while the distribution density and range of Hengmaomeng were the smallest. Furthermore, there was low-density, small-scale merchant aggregation in Fenghe New City.

\subsection{The Spatial Distribution Characteristics of the Public Reviews}

\subsubsection{The general spatial distribution characteristics of the public reviews}

The distribution of the public reviews was basically identical to the density distribution and 
showed a development trend with one core and many piece areas. The spatial distribution of the public reviews could thus be simulated with public reviews as a field calculated by a kernel density analysis in ArcGIS.

The degree of Middle Mountain City's public reviews was the highest. Its range of aggregation covered points of interest like Baihua Continent, Yangzi Street, the Memorial of the August 1 Nanchang Uprising.

The degree of Honggutan New District's public reviews and its aggregation scale were similar to those of Middle Mountain City. Honggutan New District was a subcenter of Middle Mountain City. An independent aggregation area, Fenghe New City, was found in Honggutan New District.

There was an aggregation of high public reviews merchants in Hengmaomeng, its scale was smaller than those of Middle Mountain City and Honggutan New District.

There were many catering merchants aggregating in Hengmao International and Lizhou Community etc., and they tended to develop with Middle Mountain City in a continuum.

Overall, Middle Mountain City was the absolute core area, and the other areas with high public reviews were concentrated in business districts. At the same time, public reviews in each center formed a structure of diminishing circle layers. There was also a developing trend of layer diffusion in the aggregation centers of the merchants, similar to existing conclusions in academic circles (Xiao et al., 2013). However, the number and scale of aggregation centers was small and their development was isolated. These conclusions indicate that there was an incoordination between the development of the urban catering trade and urban construction in Nanchang.

3.2.2. The spatial distribution characteristics of the public Reviews of catering merchants with different consumption

Different kinds of catering merchants have different degrees of public reviews participation because they serve different customer groups. As a result, this will lead to different spatial distributions of public reviews. Some conclusions were drawn using the basic data and the classification of consumption levels created using SPSS. There were 89 high-consumption merchants whose average consumption standard was over 118 yuan. The number of middleconsumption merchants was 1,777, and their average consumption standard was between 45 and 117 yuan, while the number of low-consumption businesses was 1,920, and their average consumption standard was between 5 and 44 yuan.

The kernel density of distribution of the 89 catering merchants with high consumption in Nanchang was obtained by kernel density analysis in ArcGIS (Figure 4).

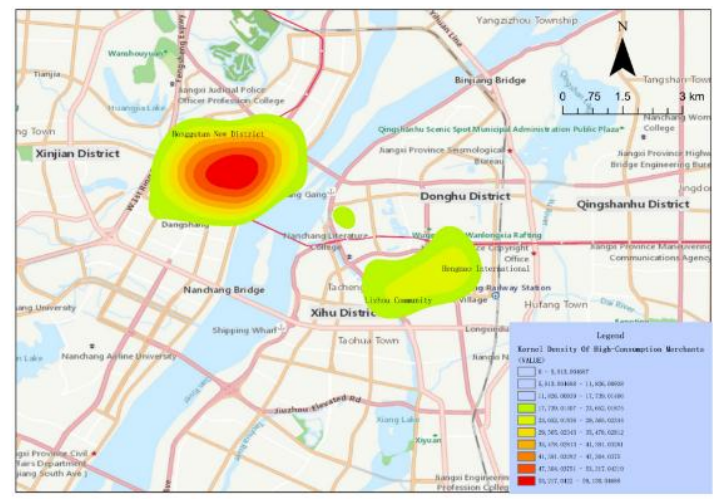

(a) Merchants

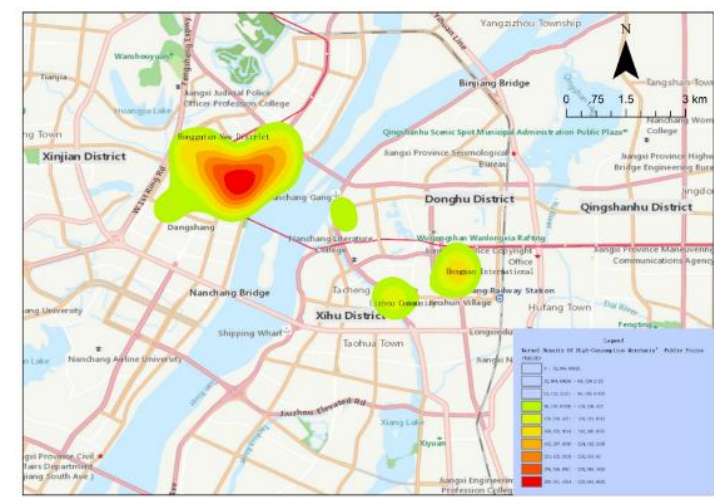

(b) Merchants' Public Reviews

Figure 4 The kernel density of the high-consumption merchants 
Honggutan New District was the core area where catering merchants with high consumption were gathered. The district radiated from Fenghuang Middle Road, Fenghe Middle Road, and Honggu Middle Road to Ganjiang Middle Road in Changbei District, and there was a large number of merchant aggregation areas in Changbei District in particular. There were also merchant aggregation areas in Hengmao International and Lizhou Community although these were low density.

Honggutan New District was an area of high public reviews with high-consumption merchants. On the other hand, Hengmao International and Lizhou Community had only a few merchants with high consumption.

The distribution of high-consumption merchants was similar to the distribution of their public reviews. This shows cooperative with Honggutan New District as the core.

The kernel density of the distribution of high-consumption merchants diffused along the circle layer uniformly, but the kernel density of the high-consumption merchants' public reviews was in significantly dispersed directions, including Fenghe New City, Qiushui Square, and Wanda Plaza. There was cooperative development of high-consumption merchants in Hengmao International and Lizhou Community albeit without the concomitant development of public reviews. There were two sub-high value points in Hengmao International and Lizhou Community.

On the whole, the high-consumption merchants were concentrated in Honggutan New District, and there was a significant dispersal trend in the distribution of the public reviews of the highconsumption merchants.

The kernel density of distribution of the 1,177 catering merchants with middle consumption in Nanchang was obtained by kernel density analysis in ArcGIS (Figure 5).

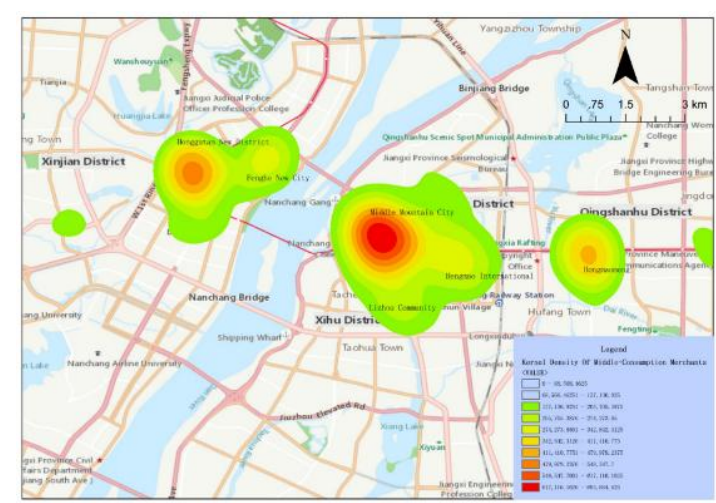

(a) Merchants

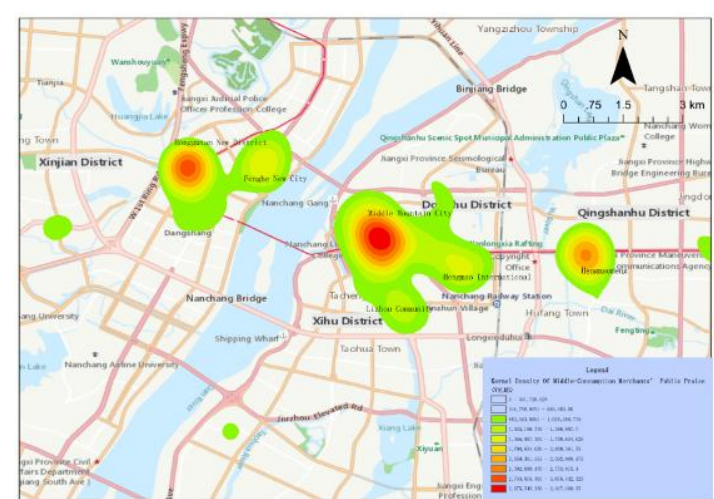

(b) Merchants' Public Reviews

Figure 5 The kernel density of the middle-consumption merchants

Middle Mountain City was the core area where catering merchants with middle consumption were gathered. Its radiation range covered Baihua Continent, Yangzi Street, and the Memorial of the August 1 Nanchang Uprising. There were some middle-consumption merchants in Honggutan New District, and there were two subcenters with cooperative developments in Fenghe New City and Honggu Middle Road. In Hengmaomeng, there were a few middleconsumption merchants although the degree of aggregation was lower than that of Honggutan New District.

Middle Mountain City was an area with high public reviews of middle-consumption merchants. 
Honggutan New District had sub-high public reviews, and Fenghe New City was a new area of high public reviews. high value of public reviews of Hengmaomeng was less than that of Honggutan New District.

The distribution of middle-consumption merchants was similar to the distribution of their public reviews. Middle Mountain City was the aggregation center, and Honggutan New District was the subcenter.

In Honggutan New District, the degree of the middle-consumption merchants' public reviews aggregation was larger than that of the middle-consumption merchants' aggregation. The middle-consumption merchants in Honggutan New District and Fenghe New City developed together, but the distribution of their public reviews was divided into two centers. The diffusion trend of middle-consumption merchants from Middle Mountain City to Hengmao International was significant. The diffusion of the middle-consumption merchants' public reviews had two directions, Hengmao International and Lizhou Community. The decay rate of high value of public reviews slowed down at Wanshou Palace. The trend of the distribution of middleconsumption merchants' public reviews was more significant than that of the middleconsumption merchants along Shanghai North Road in Hengmaomeng.

Overall, there were three aggregation centers in Middle Mountain City, Honggutan New District, and Hengmaomeng, and they were similar in terms of the high value of public reviews. However, there was a significant difference in the diffusion between the distribution and the public reviews.

The kernel density of distribution of the 1,920 catering merchants with low consumption in Nanchang was obtained by kernel density analysis in ArcGIS (Figure 6).

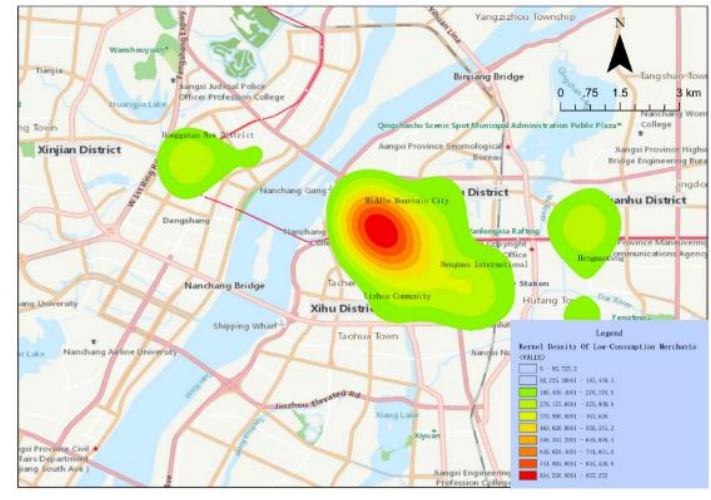

(a) Merchants

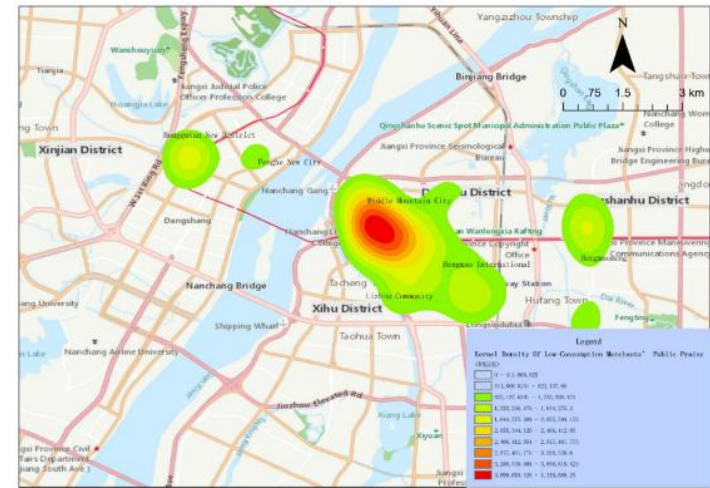

(b) Merchants' Public Reviews

Figure 6 The kernel density of the low-consumption merchants

Middle Mountain City was the core area where the catering merchants with low consumption were gathered. Its radiation range covered Baihua Continent, Wanshou Palace, and the Memorial of the August 1 Nanchang Uprising. The trend of development to Hengmao International was significant. There were a few low-consumption merchants in Honggutan New District and Hengmaomeng, and their speed of development was slow.

Middle Mountain City was a high-value public reviews area of low-consumption merchants. The high-value public reviews area shown in Hengmao International developed with Middle Mountain City. The high-value public reviews areas in Wanda Plaza and Hengmaomeng were significant. 
The distribution of low-consumption merchants was similar to the distribution of their public reviews. These merchants were gathered in Middle Mountain City, and the degree of aggregation in Hengmaomeng and Honggutan New District decreased sharply.

There was a significant trend of low-consumption merchants developing from Middle Mountain City to Hengmao International. There was however not a developing trend in terms of public reviews of low-consumption merchants in Middle Mountain City and Hengmao International; they were just developing continuously.

Overall, the distribution of low-consumption merchants and the public reviews of lowconsumption merchants were concentrated in Middle Mountain City, while in Honggutan New District and Hengmaomeng, there are very few low-consumption merchants, which led to low public reviews.

\subsection{Analysis of the Spatial Distribution of the Catering Industry in Nanchang}

From the perspective of distribution characteristics, there was a difference between the levels of the catering trade in the different areas of Nanchang.

The spatial distribution of the catering merchants in Nanchang was relatively large, but it was mainly concentrated in three regions: Middle Mountain City, Honggutan New District, and Hengmaomeng. Middle Mountain City is the core area of Nanchang civic activity, and nearby places like the Memorial of the August 1 Nanchang Uprising, Bayi Square, and Wanshou Palace are the core areas where tourists gather. Honggutan New District and Hengmaomeng are the commercial activity centers in the north and east of Nanchang, respectively, and the concentration of merchants was found to be significantly greater in these areas compared to others. The catering merchants were mainly congregated in the activity and commercial centers. Conversely, the size of the activity and commercial centers will be affected by the aggregation of the catering merchants.

Nanchang's high-consumption merchants were clustered in Honggutan New District and developed in the direction of Fenghe New City, Qiushui Square, and Wanda Plaza. Honggutan New District is the core business district of Nanchang, and the relocation of the provincial government to Kowloon Lake in Honggutan New District has led to an increase in the number of business people with a strong consumption capacity in this area. Accordingly, the location of the commercial center significantly influenced the distribution of high-consumption merchants.

In Nanchang, the middle-consumption merchants were mainly concentrated in Middle Mountain City although there were a limited number of middle-consumption merchants in Honggutan New District and Hengmaomeng. The concentration of the latter merchants was obviously smaller than that of Middle Mountain City. In Middle Mountain City, the middleconsumption merchants were found to have spread out to Lizhou Community and Hengmao International, assumedly because Middle Mountain City is not sufficient to meet the development needs of the catering merchants. As a result, middle-consumption merchant growth will be seen in Hengmao International and Lizhou Community with Middle Mountain City as the core area. Hengmao International will be another aggregation area that will see the development of future middle-consumption merchant activity.

The low-consumption merchants in Nanchang were basically congregated in Middle Mountain City. There were also a small number of low-consumption merchants in Honggutan New District and Hengmaomeng although they can be ignored. The low-consumption merchants tended to spread out to Hengmao International. In the future however, the low-consumption merchants will be clustered in the absolute core area of Middle Mountain City while those in Honggutan New District will gradually be phased out. The catering merchants in 
Hengmaomeng will extend to Hengmao International and eventually into Middle Mountain City.

On the whole, the catering merchants in Nanchang were congregated in Middle Mountain City, Honggutan New District, and Hengmaomeng. This aggregation developed because these are the centers of civic and commercial activity. The high-consumption merchants were mainly attracted by the business center while the low- and middle-consumption merchants were predominantly drawn by the significant civic activity. Because the Ganjiang River crosses Nanchang, the majority of high-consumption merchants have established their businesses in Honggutan New District. Middle Mountain City has not been sufficient to meet the needs of low- and middle-consumption merchants, and they have started to establish their trade in the area of Hengmao International. The spatial patterns of the catering trade in Nanchang showed clearly that there is considerable disparity in the catering trade in Nanchang.

\subsection{Discussion}

Through the simulation of the distribution patterns of the word-of-mouth reviews of catering merchants in Nanchang, this study found that the distribution of catering merchants in Nanchang had a certain correlation with the reputation of the merchants. Their distribution largely determined the level of word-of-mouth, while the degree of word-of-mouth determined the development direction of the catering activity. The distribution of food and the degree of word-of-mouth had circle diffusion characteristics. On the other hand, the distribution trends of the consumer merchants in urban spaces were different. The high-consumption catering merchants tended to be located in commercial activity centers, while the low- and middleconsumption merchants were mainly gathered in the civic activity centers such as Zhongshan City. This demonstrates that the internal business form and activity pattern of a city affects the spatial pattern distribution of the catering industry.

During the processing and analysis of the data, the relevant data and the attributed data of the restaurants were mined, which constitutes a unique and creative approach. The geographic information system was then used to analyze the spatial distribution patterns of the catering industry, which provided a good research method for the study of urban geography. At the same time, consideration should be given to the fact that there is an immense volume of data on the Internet. The review data was used to determine the feelings of urban residents about catering merchants as this can offer a certain level of guidance for urban planning. However, the reviews on the Dianging website comprised mostly young people, and thus limited the scope of the sample. Notwithstanding, the review data had a high level of subjectivity. In addition, the urban catering industry develops very fast, both in terms of type and quantity. At present, there is a lack of long-term accurate data, and there are thus still some shortcomings in the simulation model of the spatial distribution of the urban catering industry.

Compared with previous research on the distribution of the urban catering industry, this study simulated the spatial distribution of the Nanchang catering industry on a macroscopic scale and located abstract virtual space in geographical locations. At the same time, the use of large-scale data to determine objective laws of urban meal distribution makes the conclusions of this study more credible than those drawn by traditional theoretical models. This also presents a new paradigm for future urban research.

\section{CONCLUSION}

With the rapid development of the Internet, catering consumption models combined with Internet data will surely become the new development models for the catering industry. This will undoubtedly play a positive role in promoting the development of the catering industry. Through the use of network data, this study analyzed the spatial distribution patterns of the 
catering industry and their influencing factors, which not only provides a useful reference for the development of the catering industry, but also for city planning. Secondly, the combination of network data and urban geospatial information changes the research paradigm of traditional urban space to a certain extent. It is gradually becoming a new method or a new direction in urban planning that can also be utilized in even larger disciplines.

\section{REFERENCES}

Ding, L., Niu, X.Y., Song, X.D., 2015. Urban Spatial Studies with Big Data of Mobile Location: A Progress Review. Urban Planning International, Volume 30(4), pp. 53-58

Du, P., Bai, X.Y., Luo, J.Q., Li, E.Z., Lin, C., 2018. Advances of Urban Remote Sensing. Journal of Nanjing University of Information Science \& Technology (Natural Science Edition), Volume 10(1), pp. 16-29

$\mathrm{Hu}$, Z.Y., Zhang, Z.G., 2002. An Analysis about the Spatial Distribution of Hotels in Urban Area: Take Nanjing as a Case. Economic Geography, Volume 22(1), pp. 106-110

Lu, L., 2007. The Distribution in Space of Urban Catering and its Factors: Xi'an as an Example. Journal of Northwest University (Natural Science Edition), Volume 37(6), pp. 925-930

Li, Z.F., Yu, L., Gao, Y., Wu, Y.Z., Gong, D.P., Song, G.H., 2016. Extraction Method of Temporal and Spatial Characteristics of Residents' Trips based on Cellular Signaling Data. Transportation Standardization, Volume 2(1), pp. 51-57

Xiao, Q., Feng, Z., Lifang, X., Shoujia, Z., 2013. Methods in Urban Temporal and Spatial Behavior Research in the Big Data Era. Progress in Geography, Volume 32(9), pp. 13521361

Wall, G., Dudycha, D., Hutchinson, J., 1985. Point Pattern Analysis of Accommodation in Toronto. Annals of Tourism Research, Volume 12(4), pp. 603-618

Wang, J.F., Liao, Y.L., Liu, X., 2010. Spatial Data Analysis Tutorial. Science Press, Beijing, pp. 273-277

Wen, J., 2004. On Chinese Star-Hotels' Spatial Distribution. Commercial Research, Volume 21, pp. 154-159

Wu, Z.Q., Dai, X.Z., Wei, X.H., 2003. Review and Prospects for Study on Spatial Structure of Urban commercial Activity. Economic Geography, Volume 23(3), pp. 327-332

Wu, Z.Q., Ye, Z.N., 2016. Research on Urban Spatial Structure based on Baidu Heat Map: A Case Study on the Central City of Shanghai. City Planning Review, Volume 40(04), pp. $33-40$

Xue, D.Q., Shi, N., Gong, X.X., 2011. Spatial Features and Agglomeration of Producer Services in Xi'an City, China. Scientia Geographical Sonica, Volume 31(10), pp. 11951201

Zhen, F., Liu, H., Zheng, J., 2008. Spatial Distribution of Urban Producer Service: A Case Study of Nanjing. World Regional Studies, Volume 17(1), pp. 24-31

Zhen, F., Liu, X.X., Liu, H., 2007. Regional Urban Network Influenced by Information Technology: New Directions of Urban Studies. Human Geography, Volume 2, pp. 76-80

Zhou, S.-Y., Ji, L.-M., 2009. Commercial Space Succession in Old City of Beijing Case of Survey Line of Inner City in Beijing from 1996 to 2006. Scientia Geographical Sinica, Volume 29(4), pp. 493-499 